\title{
Cationic Polymerization of Cyclic Amines. IV. $N$-Methylazetidine
}

\author{
Etienne H. Schacht, Piet K. Bossaer, and Eric J. Goethals \\ Laboratory of Organic Chemistry, Rijksuniversiteit Gent \\ Krijgslaan 271 (S4-bis), B-9000 GENT, Belgium.
}

(Received February 12, 1977)

\begin{abstract}
The polymerization of $N$-methylazetidine (NMA) with triethyloxonium tetrafluoroborate in dichloromethane has been studied. This polymerization is characterized by an instantaneous and quantitative initiation reaction followed by a relatively fast propagation. The existence of a termination by reaction of the growing chains with amino groups of the polymer chain was shown by kinetic and viscosity measurements. The propagation constants $k_{\mathrm{p}}$ and termination constants $k_{\mathrm{t}}$ at different temperatures were calculated. The enthalpies of activation for propagation and termination are respectively $\Delta H_{\mathrm{p}} \neq=57 \mathrm{~kJ} \mathrm{~mol}^{-1}, \Delta H_{\mathrm{t}} \neq=63 \mathrm{~kJ} \mathrm{~mol}^{-1}$, and the corresponding entropies of activation are $\Delta S_{\mathrm{p}} \neq=-71 \mathrm{~J} \mathrm{~mol}^{-1} \mathrm{~K}^{-1}$ and $\Delta S_{\mathrm{t}} \neq=-117 \mathrm{~J} \mathrm{~mol}^{-1} \mathrm{~K}^{-1}$. These results have been compared with those obtained earlier for 1,3,3-trimethylazetidine.

KEY WORDS Ring-Opening Polymerization / Cationic Polymerization / Cyclic-Amine Polymerization / $N$-Methylazetidine / Termination Constant / Propagation Constant / Enthalpy of Activation / Entropy of Activation /
\end{abstract}

During the last five years several reports on the polymerization of four-membered cyclic amines, azetidines, have been published. ${ }^{1-6}$ In a previous publication we reported that the cationic polymerization of 1,3,3-trimethylazetidine (I) leads to a "living" polymer. This was explained by the fact that the basicity of the nitrogen atom in the monomer is considerably higher than that in the corresponding polymer. In addition the steric hindrance around the amino groups in the polymer is greater than that around the monomeric amino group. As a result, termination by an attack of a polymeric amino group on the active center of the growing chain is negligible compared to the propagation reaction. Similar results have been obtained by
Enikolopyan $^{1}$ and coworkers for the cationic polymerization of conidine (II). In the present work the results of a study on the cationic polymerization of $N$-methylazetidine (NMA) (III) are reported. This monomer has a basicity ${ }^{7}$ close to that of linear tertiary amines and therefore it seemed to be of interest to investigate whether or not this polymerization would also be of a living type.

\section{RESULTS}

The polymerization of $N$-methylazetidine (NMA) was carried out in dichloromethane, with triethyloxonium tetrafluoroborate (TEFB) as the initiator, at temperatures ranging from<smiles>CN1CC(C)(C)C1</smiles>

1,3,3-Trimethylazetidine (TMA)

(I)<smiles>CC(=O)N1CCCC1</smiles>

(II)<smiles>CN1CC[C@H]1C(C)(C)C</smiles>

(III) 
$0^{\circ}$ to $40^{\circ} \mathrm{C}$. Poly-NMA, as isolated from the polymerization mixture after the kinetic measurements were stopped, is a tacky substance. It is soluble in chlorinated hydrocarbons, ethanol, diluted aqueous acids, and insoluble in ether, benzene, and toluene.

\section{Time-Conversion Curves}

Time-conversion curves of polymerizations obtained for different concentrations of initiator and for varying temperatures are shown in Figures 1 and 2. The polymerizations were followed by dilatometry. At the point the dilatometric measurements were stopped, the conversion was determined by NMR spectroscopic analysis of the reaction mixture.

The first-order plots gave straight line curves in the early stages of the polymerizations only, indicating the presence of a termination reaction (Figure 3).

\section{Viscosity Measurements}

As shown in Figure 4, the reduced viscosity of the polymerization mixture continues to in-

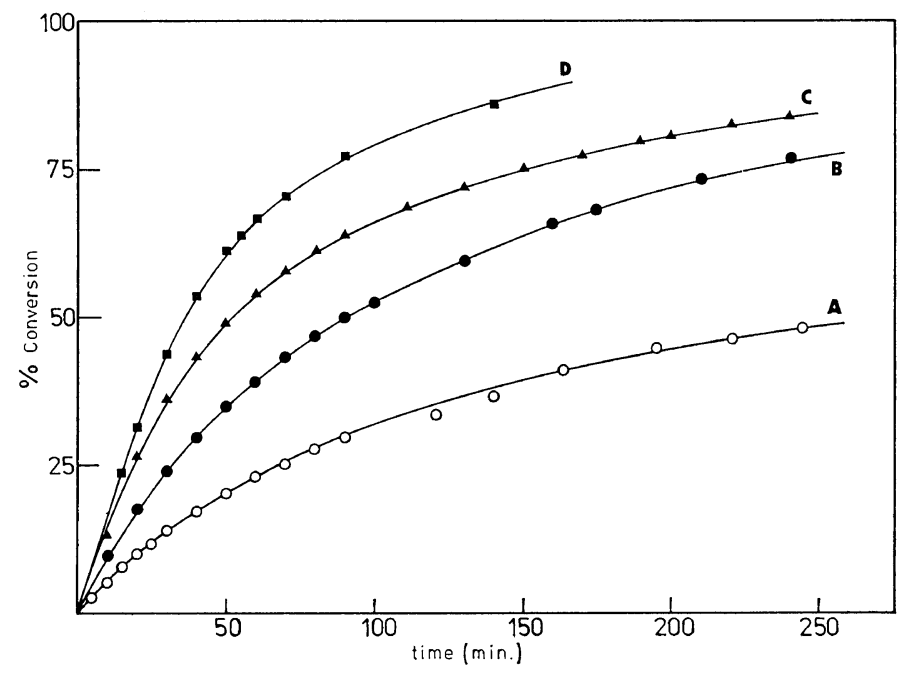

Figure 1. Time-conversion curves for the polymerization of $\mathrm{NMA}$ in $\mathrm{CH}_{2} \mathrm{Cl}_{2}$ at $30^{\circ} \mathrm{C}$. [M] $]_{0}=0.975$ $\mathrm{mol} l^{-1} ;[\mathrm{C}]_{0}=\mathrm{A}, 0.01 ; \mathrm{B}, 0.015 ; \mathrm{C}, 0.0275 ; \mathrm{D}, 0.037 \mathrm{~mol} l^{-1}$.

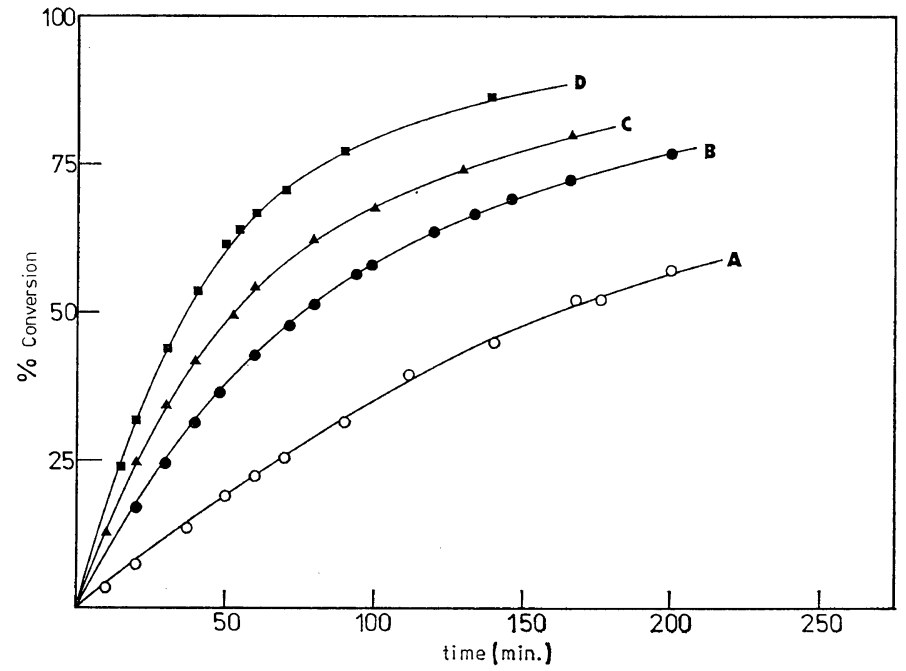

Figure 2. Time-conversion curves for the polymerization of NMA at various temperatures in $\mathrm{CH}_{2} \mathrm{Cl}_{2} . \quad[\mathrm{M}]_{0}=0.975 \mathrm{~mol}^{-1} ;[\mathrm{C}]_{0}=0.037 \mathrm{~mol} l^{-1}$; temp: A, 10; B, 20; C, 25; D, 30 ${ }^{\circ} \mathrm{C}$. 
Cationic Polymerization of Cyclic Amines. IV.

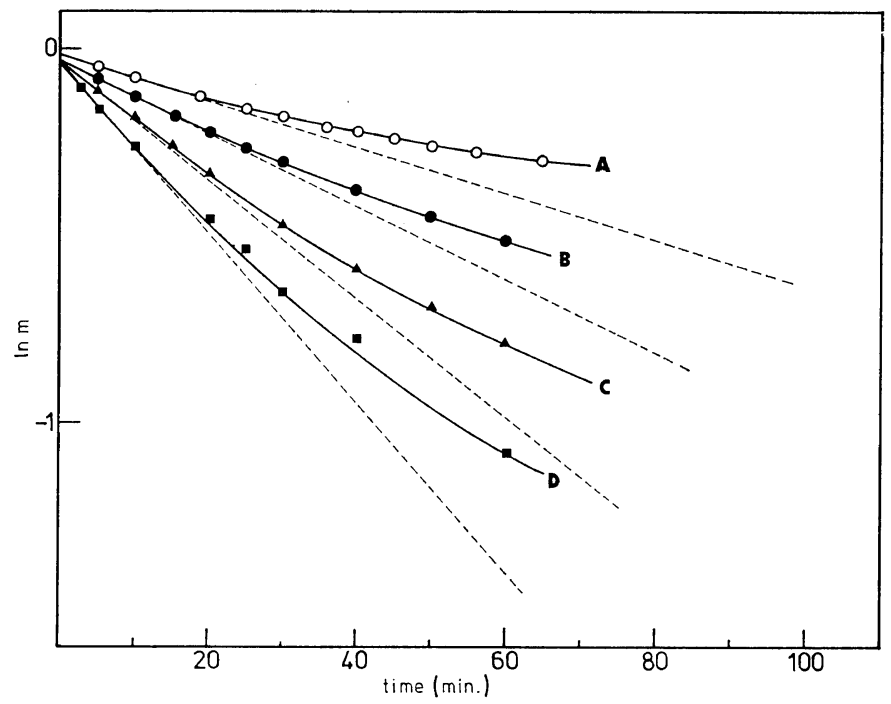

Figure 3. First-order plots of the polymerization of NMA in $\mathrm{CH}_{2} \mathrm{Cl}_{2}$ at $30^{\circ} \mathrm{C}$. Conditions are the same as shown in Figure 1.

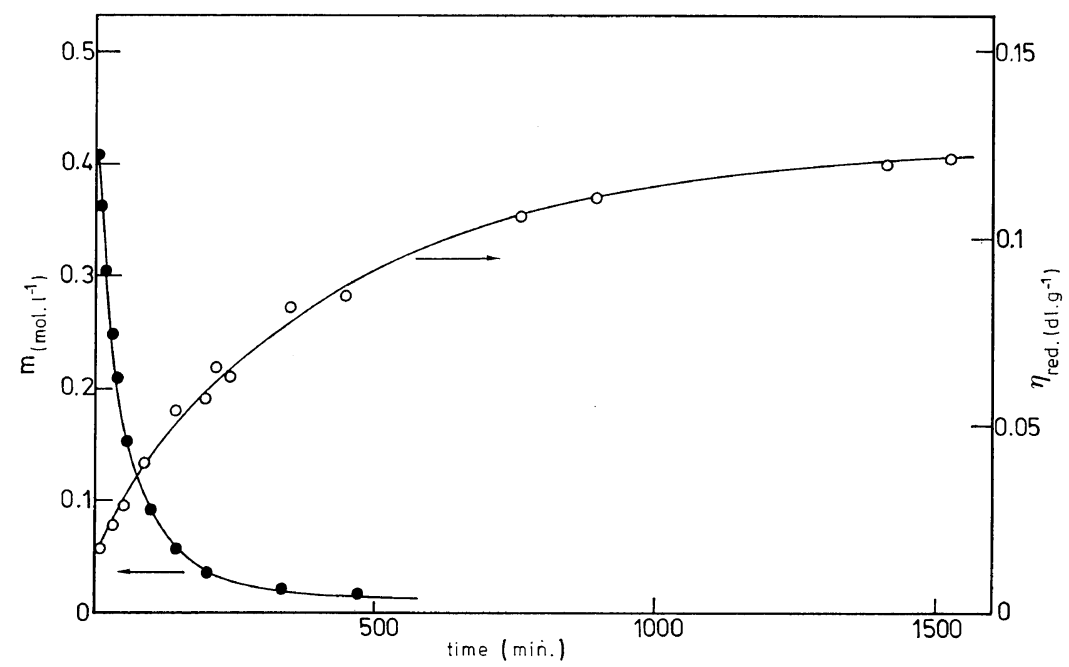

Figure 4. Viscosity of polymerizing NMA solution and time-conversion curve in $\mathrm{CH}_{2} \mathrm{Cl}_{2}$ at $30^{\circ} \mathrm{C}$. $[\mathrm{M}]_{0}=0.47 \mathrm{~mol}^{-1} ;[\mathrm{C}]_{0}=0.035 \mathrm{~mol}^{l^{-1}}$.

crease after the polymerization has reached high conversion levels, proving that the molecular weight of the polymer increases without monomer consumption.

\section{Additional Experiments}

In order to see whether, after high conversion has been attained, the polymer still contains ac- tive centers, more monomer was added to the reaction mixture. This freshly added monomer started to polymerize immediately but the rates of these second polymerizations decreased as the initiating polymer solution became older. Examples of time-conversion curves of second polymerizations are shown in Figure 5. 


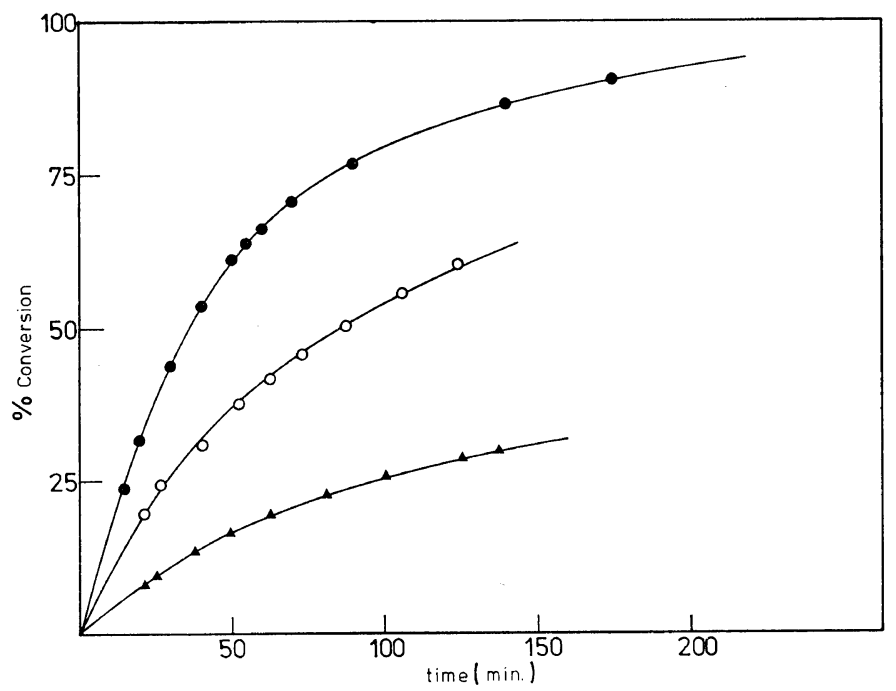

Figure 5. Second monomer addition experiments. Time-conversion curves for $\mathrm{NMA}$ in $\mathrm{CH}_{2} \mathrm{Cl}_{2}$ at $30^{\circ} \mathrm{C}$ : O, original polymerization; $\bigcirc$, monomer added $360 \mathrm{~min}$ after first initiation; $\Delta$, monomer added $600 \mathrm{~min}$ after first initiation.

\section{DISCUSSION}

\section{Initiation Reaction}

The initiation reaction in the polymerization of NMA with TEFB is obviously an alkylation of the monomer with formation of the corresponding azetidinium salt.<smiles>CCOCC</smiles>

This reaction occurs instantaneously and is quantitative as was proved by means of NMR spectroscopy. On adding an excess of TEFB to the monomer, within seconds, all monomer disappeared and the corresponding azetidinium salt was formed.

\section{Propagation Reaction}

The most plausible propagation reaction involves a nucleophilic attack of the nitrogen atom of the monomer at the $\alpha$-carbon atom of the azetidinium ion.

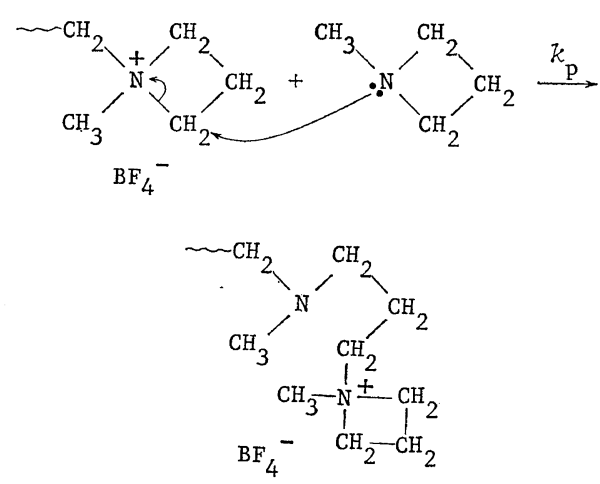

The driving force of this reaction is opening of the strained active chain end, and monomer is acting as a nucleophile that causes the ring opening.

The rate of polymerization $R_{\mathrm{p}}$, at any moment, is given by:

$$
R_{\mathrm{p}}=-\frac{\mathrm{d}[\mathrm{M}]}{\mathrm{d} t}=k_{\mathrm{p}}\left[P_{\mathrm{n}}^{+}\right][\mathrm{M}]
$$

where $[\mathrm{M}]$ is the monomer concentration and $\left[\mathrm{P}_{\mathrm{n}}{ }^{+}\right]$ the concentration of growing chains.

The slope of the tangent at the first-order plots at any time is given by

$$
\frac{\mathrm{d} \ln [\mathrm{M}]}{\mathrm{d} t}=\frac{1}{[\mathrm{M}]} \frac{\mathrm{d}[\mathrm{M}]}{\mathrm{d} t}
$$

Equations 1 and 2 gives 
Cationic Polymerization of Cyclic Amines. IV.

$$
\frac{\mathrm{d} \ln [\mathrm{M}]}{\mathrm{d} t}=-k_{\mathrm{p}}\left[P_{\mathrm{n}}^{+}\right]
$$

Because the initiation reaction is instantaneous and quantitative, at $t=0,\left[P_{\mathrm{n}}^{+}\right]=[\mathrm{C}]_{0}$ and eq 3 leads to

$$
\lim _{t \rightarrow 0} \frac{\mathrm{d} \ln [\mathrm{M}]}{\mathrm{d} t}=-k_{\mathrm{p}}[\mathrm{C}]_{0}
$$

with $[C]_{0}=$ the initial concentration of TEFB. By plotting the tangent of the initial slope of the first-order plots $v s$. the corresponding $[\mathrm{C}]_{0}$ values, the $k_{\mathrm{p}}$ values can be determined. The results are given in Table I.

\section{Termination Reaction}

If there had been no termination reaction, the concentration of growing species would have remained constant throughout the polymerization and be equal to $[\mathrm{C}]_{0}$. First-order plots should give straight lines, but as shown in Figure 3 this is not the case. Also the second monomer addition experiments demonstrate that the concentration of active species decreases as a function of time. These observations are in concordance with the occurrence of a termination reaction. The most plausible mechanism for this termination reaction is that the growing species is attacked by an amino function of the polymer chain instead of monomer. In this way the strained azetidinium ion, which provides the driving force for propagation, is transformed into a linear (or eventually macrocyclic) nonstrained and therefore unreactive quaternary ammonium salt.

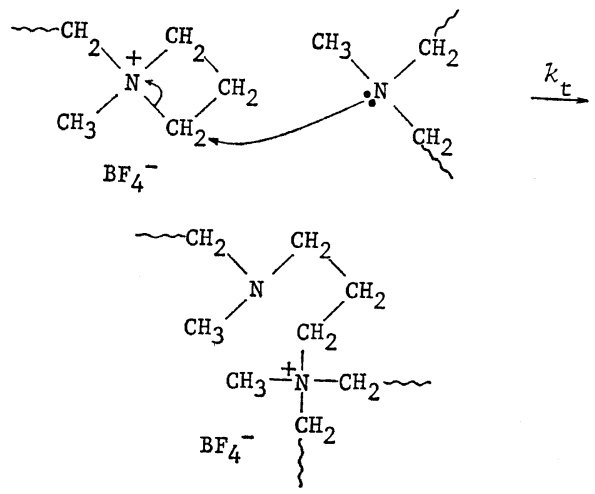

If the reacting amino group is part of another polymer chain, branched structures will be formed. As a consequence the viscosity must con- tinue to increase even at high monomer conversion because of the progressing termination reaction. As shown in Figure 4 this phenomenon was indeed observed.

From the change in polymerization rate $R_{\mathrm{p}}$, as a function of time, the propagation and termination rate constants $k_{\mathrm{p}}$ and $k_{\mathrm{t}}$ can be calculated.

The value of $R_{\mathrm{p}}$ at any time $t$, is the slope of the tangent at the corresponding point on the time-conversion curve. If the termination occurs by reaction of the active species with an arbitrary polymeric amino group (the concentration of which is equal to that of monomer already polymerized) the rate of termination $R_{\mathrm{t}}$ will be given by

$$
R_{\mathrm{t}}=-\frac{\mathrm{d}\left[P_{\mathrm{n}}^{+}\right]}{\mathrm{d} t}=k_{\mathrm{t}}\left[P_{\mathrm{n}}^{+}\right]\left([\mathrm{M}]_{0}-[\mathrm{M}]\right)
$$

from which

$$
\ln \left[P_{\mathrm{n}}^{+}\right]=\ln \left[P_{\mathrm{n}}^{+}\right]_{0}-k_{\mathrm{t}} \int_{0}^{t}\left([\mathrm{M}]_{0}-[\mathrm{M}]\right) \mathrm{d} t
$$

Since the initiation reaction is immediate and quantitative the initial concentration of growing chains $\left[\mathrm{P}_{\mathrm{n}}^{+}\right]_{0}$ is equal to $[\mathrm{C}]_{0}$, thus

$$
\ln \left[P_{\mathrm{n}}^{+}\right]=\ln [\mathrm{C}]_{0}-k_{\mathrm{t}} \int_{0}^{t}\left([\mathrm{M}]_{0}-[\mathrm{M}]\right) \mathrm{d} t
$$

or

$$
\left[P_{\mathrm{n}}^{+}\right]_{\mathrm{t}}=[\mathrm{C}]_{0} \exp \left\{-k_{\mathrm{t}} \int_{0}^{t}\left([\mathrm{M}]_{0}-[\mathrm{M}]\right) \mathrm{d} t\right\}
$$

$\int_{0}^{t}\left([\mathrm{M}]_{0}-[\mathrm{M}]\right) \mathrm{d} t$ corresponds to the area $I$ under the time-conversion curve up to time $t$, if the molar concentration of monomer which has been polymerized $\left([\mathrm{M}]_{0}-[\mathrm{M}]\right)$ is plotted on the $y$-axis. Equation 8 can be written as

$$
\left[P^{+}\right]=[\mathrm{C}]_{0} \mathrm{e}^{-k_{\mathrm{t}} I}
$$

Combination of eq 9 and 1 gives

or

$$
R_{\mathrm{p}}=k_{\mathrm{p}}[\mathrm{M}][\mathrm{C}]_{0} \mathrm{e}^{-k_{\mathrm{t}} I}
$$

$$
\ln \frac{R_{\mathrm{p}}}{[\mathrm{M}][\mathrm{C}]_{0}}=\ln k_{\mathrm{p}}-k_{\mathrm{t}} I
$$

By plotting $R_{\mathrm{p}} /[\mathrm{M}][\mathrm{C}]_{0}$ vs. the corresponding $I$, a straight line with a slope equal to $k_{\mathrm{t}}$ and intercept of the ordinate equal to $\ln k_{\mathrm{p}}$ is obtained. Figure 6 shows such plots for polymerizations carried out at various temperatures. The values 


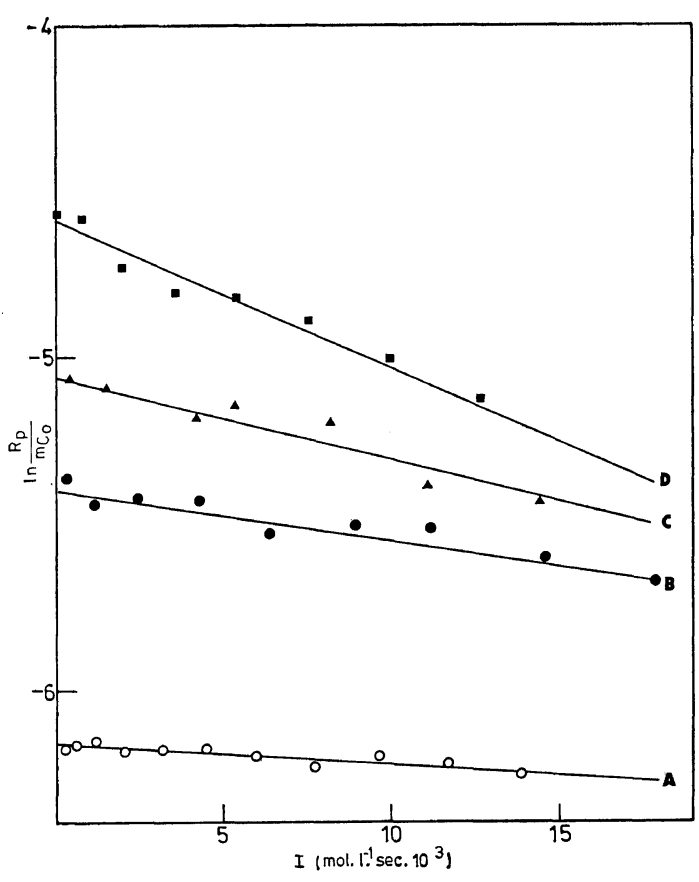

Figure 6. Determination of $k_{\mathrm{p}}$ and $k_{\mathrm{t}}$ at different temperatures according to eq 11 .

of $k_{\mathrm{p}}$ and $k_{\mathrm{t}}$ obtained from those curves are summarized in Table I.

According to eq 12,

$$
\ln \frac{k_{\mathrm{p}}}{T}=\ln \frac{k^{*}}{h}+\frac{\Delta S^{\neq}}{R}-\frac{\Delta H^{\neq}}{R T}
$$

$k^{*}=$ Boltzman constant,$\quad h=$ Planck constant the enthalpy of activation $\Delta H^{\neq}$and the entropy of activation $\Delta S^{\neq}$for the propagation and the termination reactions were determined by plotting $\ln k_{\mathrm{p}} / T$ and $\ln k_{\mathrm{t}} / T$ vs. $1 / T$, respectively (Figure 7). These thermodynamic parameters are brought together in Table II. For comparison, the corresponding values for 1,3,3-trimethylazetidine (TMA) have been added.

At room temperature the ratio $k_{\mathrm{p}} / k_{\mathrm{t}}$ for NMA is ca. 230. This means that the monomeric amino function is 230 times more reactive than the polymeric amino function in its reaction with

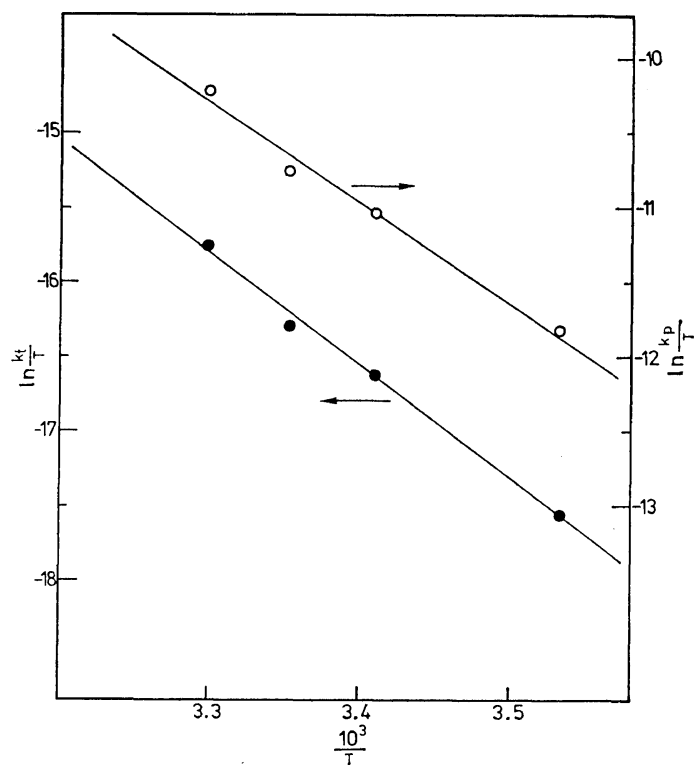

Figure 7. Determination of thermodynamic parameters according to eq 12 .

Table I. Rate constants for propagation and termination

\begin{tabular}{cccccc}
\hline $\begin{array}{c}{[\mathrm{M}]_{0},} \\
\mathrm{~mol} l^{-1}\end{array}$ & $\begin{array}{c}{[\mathrm{C}]_{0} \times 10^{2},} \\
\mathrm{~mol} l^{-1}\end{array}$ & $\begin{array}{c}\text { Temp, } \\
{ }^{\circ} \mathrm{C}\end{array}$ & $\begin{array}{c}k_{\mathrm{p}} \times 10^{2}, \mathrm{a} \\
l \mathrm{~mol}^{-1} \mathrm{sec}^{-1}\end{array}$ & $\begin{array}{c}k_{\mathrm{p}} \times 10^{2}, \mathrm{~b} \\
l \mathrm{~mol}^{-1} \mathrm{sec}^{-1}\end{array}$ & $\begin{array}{c}k_{\mathrm{t}} \times 10^{5}, \mathrm{~b} \\
l \mathrm{~mol}^{-1} \mathrm{sec}^{-1}\end{array}$ \\
\hline 0.975 & 1.00 & 30 & 1.08 & 1.09 & 4.30 \\
0.970 & 1.50 & 30 & 1.06 & 1.02 & 4.44 \\
0.975 & 1.84 & 30 & 0.95 & 0.98 & 4.20 \\
0.975 & 2.67 & 30 & 0.96 & 0.9 & 4.77 \\
0.974 & 3.66 & 30 & 1.10 & 1.08 & 4.45 \\
0.487 & 3.66 & 30 & 0.98 & 0.63 & 2.50 \\
0.979 & 3.70 & 25 & 0.68 & 0.49 & 2.00 \\
1.095 & 2.06 & 20 & 0.48 & 0.50 & 1.70 \\
0.976 & 2.76 & 20 & 0.47 & 0.45 & 1.56 \\
0.975 & 3.68 & 20 & 0.46 & 0.21 & 0.65 \\
0.975 & 3.68 & 10 & 0.23 & & \\
\hline
\end{tabular}

a Determined from initial slope of first-order plots.

b Determined according to eq 11 . 
Cationic Polymerization of Cyclic Amines. IV.

Table II. Thermodynamic parameters for the polymerization of NMA and TMA

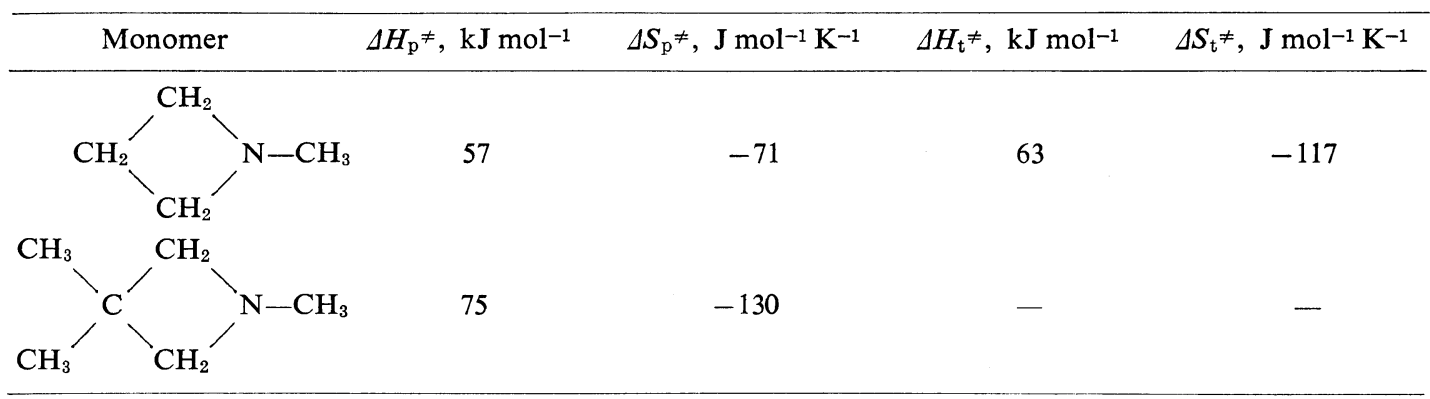

the azetidinium ion. Since the basicities of these two amino functions are not very different, this leads to the conclusion that basicity is not the major factor that determines the rates of these reactions. It is believed that steric hindrance around the nucleophilic nitrogens is the rate determining factor. Due to its cyclic structure, the monomeric amino function is very little sterically hindered compared with the polymeric ones. This influence of steric hindrance is reflected in the marked difference between $\Delta S_{\mathrm{p}}{ }^{*}$ and $\Delta S_{\mathrm{t}}{ }^{*}$. The importance of steric hindrance is confirmed on comparion of the polymerization of NMA with that of TMA. The latter monomer polymerizes much more slowly than the former because it shows not only a higher $\Delta H_{\mathrm{p}}^{\neq}$but also a much more negative $\Delta S_{\mathrm{p}}{ }^{*}$. This can be attributed to the much higher steric hindrance caused by the gem-dimethyl groups on the monomer as well as on the active species.

The effect of these gem-dimethyl groups is even more pronounced in the polymer since poly-TMA did not show any sign of termination even at $80^{\circ} \mathrm{C}$.

\section{CONCLUSION}

The cationic polymerization of NMA with TEFB is characterized by a very fast initiation reaction followed by a relatively fast propagation and a slow termination, occurring between the active species and the amino functions of the polymer. It can therefore be classified under the "suicidal" polymerizations ${ }^{8}$ since the reaction is killed by its own polymer. The transfer of the onium salt from active species to the polymer chains has already been observed with other four-membered heterocycles such as the thietanes $^{9}$ and selenetanes. ${ }^{10}$ Quite recently this has also been found to occur in the polymerization of oxetane. ${ }^{11}$ Therefore it may be safely accepted that this is a general behavior in cationic ring-opening polymerization of fourmembered heterocycles. In the case of thietanes it has been found that the relative importance of the termination compared with propagation is greatly influenced by the presence of substituents on the monomer. ${ }^{12}$ From this paper it follows that the same effect is found in the case of azetidines: TMA polymerizes much more slowly than NMA but with the former monomer the termination is no more detectable. Although the absolute rate of polymerization decreases, it appears that the presence of substituents retards the termination more than it does the propagation.

\section{EXPERIMENTAL}

\section{Materials}

$N$-Methylazetidine (NMA) was prepared by ring closure of $N$-methyl-3-hydroxypropylamine, according to the method of Gabriel. ${ }^{13}$ The amino alcohol was synthesized as described by Schloegl. ${ }^{14}$ The monomer was dried on sodium and purified by fractional distillation; bp $41^{\circ} \mathrm{C}$ (lit. ${ }^{13} 40^{\circ} \mathrm{C}$ ). It was freshly distilled just before use. Gas chromatographic analysis indicated a purity higher than $99.9 \%$.

Triethyloxonium tetrafluoroborate (TEFB) was prepared as described by Meerwein ${ }^{15}$ and purified by several reprecipitations with ether from its dichloromethane solution. It was stored at $-30^{\circ} \mathrm{C}$ as a solution in dichloromethane.

\section{Polymerization Procedure}

The kinetic measurements were carried out 
by dilatometry. After solvent, monomer, and initiator had been introduced, the dilatometer was connected to a vacuum line, the solution being cooled in liquid nitrogen. The apparatus was sealed off under vacuum and then put in a water bath thermostatted at the desired temperature. The decrease of the volume of the reaction mixture during polymerization was determined by monitoring the level of the solution in the capillary tube by means of a cathetometer. The concentrations of monomer and polymer at the end of the dilatometric measurements were determined by NMR spectroscopy with a Varian HR-300 apparatus. The triplet at $\delta 3.12 \mathrm{ppm}$ corresponding to the $\alpha$-methylene groups in NMA was shifted to $\delta 2.25 \mathrm{ppm}$ in the polymer. The ratio of monomer to polymer was obtained by integration of these methylene protons.

Acknowledgment. Etienne $\mathrm{H}$. Schacht thanks the Nationaal Fonds voor Wetenschappelijk Onderzoek and P. Bossaer the IWONL for financial support.

\section{REFERENCES}

1. E. F. Razvodowskij, A. V. Nekrasov, A. A. Berlin, A. T. Ponomarenko, and N. S. Enikolopyan, Dokl. Akad. Nauk. USSR, 198, 894 (1971).

2. E. H. Schacht and E. J. Goethals, Makromol.
Chem., 167, 155 (1973).

3. E. J. Goethals and E. H. Schacht, J. Polym. Sci., Polym. Lett. Ed., 11, 497 (1973).

4. I. S. Morozova, E. F. Razvodovskii, R. V. Nekrasov, M. A. Markevich, A. A. Berlin, S. P. Petrosyants, V.A. Afanas'ev, V.S. Boydanov, and N. S. Enikolopyan, Dokl. Akad. Nauk. USSR, 209, 153 (1973).

5. E. H. Schacht and E. J. Goethals, Makromol. Chem., 175, 3447 (1974).

6. E. F. Razvodovskii, A. A. Berlin, A. V. Nekrasov, L. M. Pushchayeva, N. G. Puchkova, and N.S. Enikolopyan, Vysokomol. Soedin., Ser. A, 15, 2219 (1973).

7. A. T. Bottini and J. D. Roberts, J. Am. Chem. Soc., 80, 5203 (1958).

8. E. J. Goethals, J. Polym. Sci., Polym. Symp. $E d$., in press.

9. E. J. Goethals and W. Drijvers, Makromol. Chem., 136, 73 (1970).

10. E. J. Goethals, E. Schacht and D. Tack, $J$. Polym. Sci., Part A-1, 10, 533 (1972).

11. P. E. Black and D. J. Worsfold, Canadian J. of Chem., 54 (No. 21), 3325 (1976).

12. E. J. Goethals, W. Drijvers, D. Van Ooteghem, and A. M. Buyle, J. Macromol. Sci.-Chem., A7, 1375 (1973).

13. S. Gabriel, Ber., 21, 566 (1888).

14. K. Schloegl and R. Schloegl, Monatsh. Chem., 95(3), 922 (1964).

15. H. Meerwein, E. Battenberg, H. Gold, E. Pfeil, and G. Willfang, J. Prakt. Chem., 154, 83 (1939). 